\title{
Application of Artificial Neural Networks for developing a crack detection algorithm
}

\author{
[ B Prakruthi Gowd, Divya Vani B, Dr. Manjunath N Hegde]
}

\begin{abstract}
As the demand for the safety and functionality of civil structures is increasing continuously, structure health monitoring (SHM) has now become more and more important. Recent developments in artificial intelligence is offering great potentials to develop a more efficient, reliable, and robust structure damage detection system. In this paper, the application of artificial neural networks is investigated and an intelligent structural damage detection algorithm is developed and also an uncertainty study is made to check the robustness of the algorithm developed.
\end{abstract}

Keywords-Damage Detection, Artificial Neural Network, Sensitivity Analysis.

\section{Introduction}

When a structure suffers from damages, its dynamics properties can change especially, crack damage can cause a stiffness reduction, with inherent changes in natural frequencies, an increase in modal damping and a change of the modal shapes. During the last few decades, considerable work has been carried out for crack detection in different types of structures using vibration analysis in general and Artificial Intelligence (AI) in particular. The possible directions for research can be obtained from the analysis of the literature cited in this section. From the published works it is seen that the idea regarding damage detection in different systems varies widely. In spite of the fact that, there is a wide variation in development of damage detection methodology next section presents the review of the literature pertaining to damage detection using AI.

Sahin and Shenoi [1] presents a damage detection algorithm using a combination of global (changes in natural frequencies) and local (curvature mode shapes) vibrationbased analysis data as input in artificial neural networks (ANNs) for location and severity prediction of damage in beam-like structures. Rosales et al. [2] have presented the solution of the inverse problem with a power series technique (PST) and the use of artificial neural networks (ANNs) for detection of crack in the cantilever beam.

B Prakruthi Gowd

Assistant Professor, Vidya Jyothi Institute of Technology Hyderabad, India

Divya Vani B

Assistant Professor, Vidya Jyothi Institute of Technology Hyderabad, India

Dr. Manjunath N. Hegde (Dr. M. N. Hegde)

Dean-Academic \& Professor, Dr. Ambedkar Institute of Technology Bengaluru, India
Bakhary et al. [3] have explained a statistical approach to take into account the effect of uncertainties in developing an ANN model. Liu et al. [4] have done his research in both direct problem and inverse problem i.e., the frequency responses of a cracked medium subjected to an impact loading and the back-propagation neural networks. Parhi and Dash [5] have attempted to contribute towards the dynamic behaviour of a beam structure containing multiple transverse cracks using neural network controller and very well explained about it. Das and Parhi [6] have extended the application of neural network technique for studying the fault diagnosis of a cracked cantilever beam. Saeed, Galybin and Popov [7] have explained their approach in depicting the different artificial intelligence techniques for crack identification in curvilinear beams, which are mainly based on changes in vibration characteristics. Mahmoud and Kiefa [8] have also presented general regression neural networks (GRNN) to solve the inverse vibration problem of cracked structures. Oz and Ozkaya [9] have explained about the transverse vibration of a Euler-Bernoulli type axially moving beam for which the new value of flexural stiffness and mean velocities, frequencies and stability borders are determined using ANN. Nazari and Baghalian [10] have presented a new approach for crack detection in symmetric beams. FEM was used to obtain natural frequencies of beam in different condition of cracks. Based on data were obtained from FEM, two distinct Artificial Neural Networks were trained for crack location and depth detection in some different conditions and then were tested. Finally using an algorithm based on first vibration mode shape of structure, locations and depths of cracks have been identified with good approximations.

The aim of the present investigation is to propose an artificial intelligent technique, which can be capable to predict the presence of cracks both location and severity in vibrating structures.

\section{Development of Models and Extraction of Modal Properties using Ansys.}

\section{A. Methodology}

The main aim of this work is to model beam like structures (flats) with fixed end condition which include both damaged and undamaged once in a FEM package software namely ANSYS and the modal analysis is carried out in order to obtain the natural frequencies and mode shapes (deformed shapes).

The variation of these natural frequencies and mode shapes have been analysed for different cases of the damaged structure with respect to the undamaged one so that they can be used further in developing various damage detection algorithms. 
Proc. of Seventh International Conference On Advances in Civil, Structural and Mechanical Engineering -ACSM 2017 Copyright (c) Institute of Research Engineers and Doctors, USA .All rights reserved.

ISBN: 978-1-63248-135-1 doi: 10.15224/ 978-1-63248-135-1-41

\section{B. Model Specifications, Cases studied and Procedure}

The geometric and material properties of the Flat along with the cases studied for the work is as given in Table I and Figure 1 shows the Fixed Flat model along with the cross section:

TABLE I. MODEL SPECIFICATION \& CASES

\begin{tabular}{|c|c|}
\hline \multicolumn{2}{|c|}{ Geometric Properties } \\
\hline Length of Flat & $3000 \mathrm{~mm}$ \\
\hline Depth of Flat & $200 \mathrm{~mm}$ \\
\hline Width of Flat & $50 \mathrm{~mm}$ \\
\hline End Conditions of Flat & Both ends Fixed \\
\hline \multicolumn{2}{|c|}{ Material Properties } \\
\hline \begin{tabular}{|c|c|}
\hline \multicolumn{2}{|c|}{$210 \mathrm{GPa}$} \\
\hline Young's Modulus & $7850 \mathrm{Kg} / \mathrm{m} 3$ \\
\hline Density & Cases \\
\hline Poisson's Ratio & Varies from 10mm to 120mm (increasing at \\
\hline $\begin{array}{c}\text { Crack } \\
\text { Depths }\end{array}$ & an interval of 10 mm) (12 varying depths) \\
\hline $\begin{array}{c}\text { Crack } \\
\text { Locations }\end{array}$ & Varies from L/2 to L/16 from the fixed end \\
(7 different locations)
\end{tabular} \\
\hline
\end{tabular}

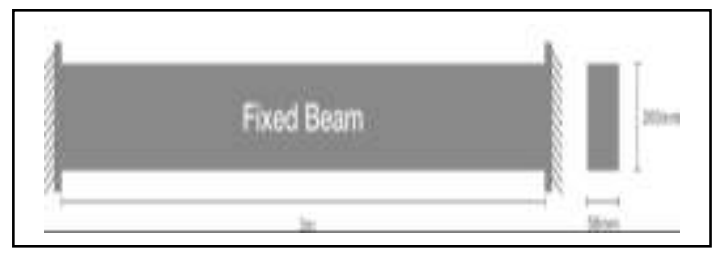

Figure 1. Fixed Beam Model

\section{Development of Artificial Neural Network Algorithm for Single Crack Detection}

The ANN models developed in this work are based on feed forward backpropagation network type with three input parameters and two output parameters.

The input parameters used are as follows:

- $\quad$ Relative first natural frequency = "rfnf";

- $\quad$ Relative second natural frequency = "rsnf";

- $\quad$ Relative third natural frequency = "rtnf";

The output parameters used are as follows;

- $\quad$ Relative crack location = "rcl"

- Relative crack depth = "rcd"

The back proposition neural network has one input layer and one output layer and different amount of hidden layers. The input layer contains three neurons and the output layer contains two neurons. Whereas the hidden layers contain varying layers of neurons. The neurons associated with the input layer of the network represents the first three relative natural frequencies and the neurons associated with the output layer of network represents the relative crack depths and relative crack location.

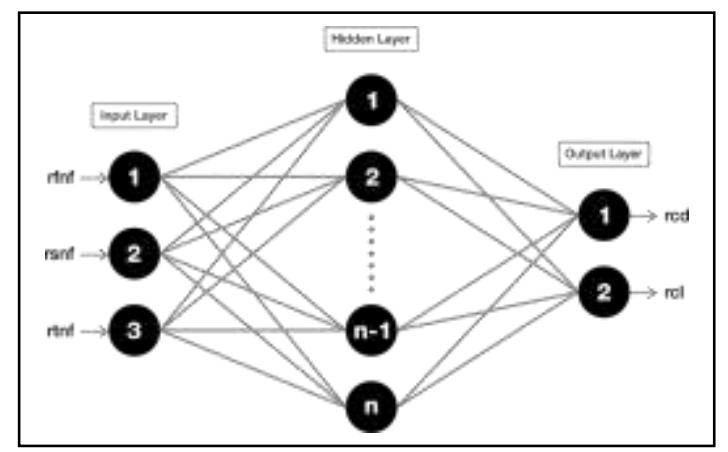

Figure 2. Neural Network Model.

Six different ANN Algorithm are developed using different number of layers and neurons in each layer and the best of them is chosen for further discussion. The network properties and the training parameters of the ANN algorithm are as below.

\section{A. Network Properties}

- Network Type: Feed Forward Backpropagation algorithm

- Training Function: TRAINLM (LevenbergMarquardt backpropagation)

- Adaption Learning Function: LEARNGDM

- Performance Function: MSE (Mean Squared Normalised)

- Transfer Function: TANSIG

- Number of Hidden Layers: 1 in first 3 Cases and 2 in the next 3 Cases

- Number of Neurons in each layer: 8, 10 and 12 respectively

\section{B. Data Division (Random)}

- $\quad$ Training Data: 70\% (58 Samples)

- Validation Data: $15 \%$ (13 Samples)

- Test Data: $15 \%$ (13 Samples)

\section{Training Properties}

- Show Window: TRUE

- Show Command Line: FALSE

- Show: 25

- Epochs: 25

- Time: Inf

- Min Grad: 1e-05

- Max Fail: 1000

- Mu: 0.001

- Mu dec: 0.1

- Mu inc: 10

- Mu Max: 10000000000

\section{Results and Discussion}

Six different ANN models were developed and the results obtained are as shown in Table II. The best ANN Algorithm out of the six network developed is the one that has the highest percentage of $\mathrm{R}^{2}$ value. 
TABLE II. STRUCTURE AND PERFORMANCE OF DIFFERENT ANN MODELS DEVELOPED

\begin{tabular}{|c|c|c|c|c|}
\hline $\begin{array}{c}\text { Sl. } \\
\text { no }\end{array}$ & $\begin{array}{c}\text { Number of } \\
\text { Hidden Layers }\end{array}$ & $\begin{array}{c}\text { Number of } \\
\text { Neurons }\end{array}$ & $\begin{array}{c}\text { ANN } \\
\text { structure }\end{array}$ & $\begin{array}{c}\mathbf{R}^{2} \text { value } \\
\text { in \% }\end{array}$ \\
\hline 1 & 1 & 8 & $3-8-2$ & 97.82 \\
\hline 2 & 1 & 10 & $3-10-2$ & 98.23 \\
\hline 3 & 1 & 12 & $3-12-2$ & 97.5 \\
\hline 4 & 2 & 8 & $3-8-8-2$ & 95.97 \\
\hline 5 & 2 & 10 & $3-10-10-2$ & 97.3 \\
\hline 6 & 2 & 12 & $3-12-12-2$ & 97.6 \\
\hline
\end{tabular}

The 3-10-2 ANN Structure was found to be the best suitable ANN Structure model for crack detection with a $98.23 \% \mathrm{R}^{2}$ value.

The results obtained from the ANN Model developed are in Table III (only few cases). Also the $\mathrm{R}^{2}$ value are as shown in Table IV.

TABLE III. STRUCTURE AND PERFORMANCE OF DIFFERENT ANN MODELS DEVELOPED

\begin{tabular}{|c|c|c|c|c|}
\hline $\begin{array}{c}\text { Case } \\
\text { No. }\end{array}$ & \multicolumn{2}{|c|}{ Original } & \multicolumn{2}{c|}{ ANN } \\
\hline & $r c d$ & $r c l$ & $r c d$ & $r c l$ \\
\hline 1 & 0.05 & 0.5 & 0.07519 & 0.24083 \\
\hline 2 & 0.1 & 0.25 & 0.07943 & 0.27894 \\
\hline 3 & 0.15 & 0.16667 & 0.11177 & 0.21126 \\
\hline 4 & 0.2 & 0.125 & 0.17028 & 0.07495 \\
\hline 5 & 0.25 & 0.1 & 0.23316 & 0.08305 \\
\hline 6 & 0.3 & 0.08333 & 0.29177 & 0.08197 \\
\hline 7 & 0.35 & 0.0625 & 0.34208 & 0.06834 \\
\hline 8 & 0.4 & 0.5 & 0.40433 & 0.5 \\
\hline 9 & 0.45 & 0.25 & 0.45149 & 0.25281 \\
\hline 10 & 0.5 & 0.16667 & 0.54498 & 0.17558 \\
\hline
\end{tabular}

It can be seen for the Table III that the results obtained from the Artificial Neural network model are in close proximity with the outputs obtained from the FEA results. Thus, the developed ANN crack detection model can be effectively used in damage detection and a continuous structural health monitoring system can be developed for any system.

TABLE IV. R $\mathrm{R}^{2}$ VALUE FOR THE ANN MODEL DEVELOPED

\begin{tabular}{|c|c|c|}
\hline \multirow{2}{*}{ Type } & \multicolumn{2}{|c|}{ R2 } \\
\cline { 2 - 3 } & rcd & rcl \\
\hline ANN Model & $98.30 \%$ & $92 \%$ \\
\hline
\end{tabular}

Note: A $0.05 \%$ level of significance i.e., a $95 \%$ level of confidence is assumed in determining the $R^{2}$ values

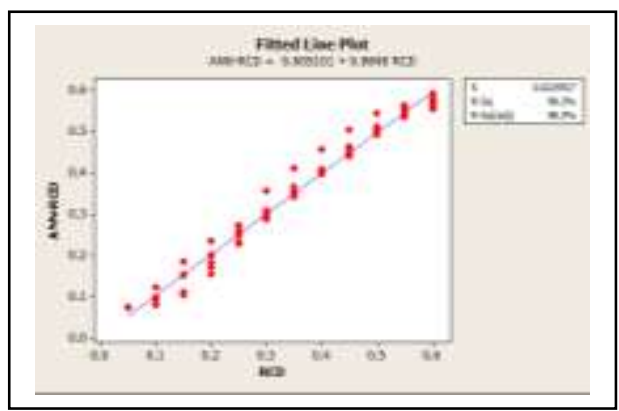

Figure 3. Regression Plots for outputs (rcd) for the ANN Model developed

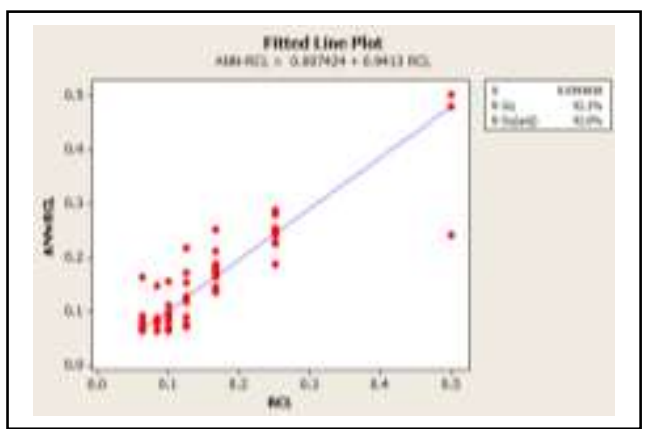

Figure 4. Regression Plots for outputs (rcd) for the ANN Model developed.

It can also be seen for the Table IV and Figure 3 and 4 that the results obtained from the ANN model has the $\mathrm{R}^{2}$ value are very good for the determination of both relative crack depths and relative crack locations. Thus ANN model can be effectively used in damage detection since it produces the best results for finding both red and $\mathrm{rcl}$.

\section{v. Sensitivity Analysis on the ANN Model Developed}

In order to know the robustness of the Artificial Neural Network developed a sensitivity analysis has been made. This is carried out by changing the values of relative first natural frequency, relative second natural frequency and relative third natural frequency by $0.1 \%$ one after the other respectively. The details of the results obtained in terms of the $\mathrm{R} 2$ values are tabulated in Table V. Also the comparison of these values have been shown in Figure 5 and 6 for rcd and $\mathrm{rcl}$ respectively.

TABLE V. R ${ }^{2}$ VALUE AFTER SENSITIVITY ANALYSIS FOR THE ANN MODEL DEVELOPED

\begin{tabular}{|c|c|c|c|}
\hline \multirow{2}{*}{$\begin{array}{c}\text { SL } \\
\text { No }\end{array}$} & \multirow{2}{*}{ Type } & \multicolumn{2}{|c|}{ R2 } \\
\cline { 3 - 4 } & & rcd & rcl \\
\hline 1 & ANN Model & $98.30 \%$ & $92 \%$ \\
\hline 2 & 0.1\% increase in rfnf & $98.20 \%$ & $85.70 \%$ \\
\hline 3 & 0.1\% increase in rsnf & $98.20 \%$ & $90.70 \%$ \\
\hline 4 & 0.1\% increase in rtnf & $98.20 \%$ & $89.20 \%$ \\
\hline
\end{tabular}

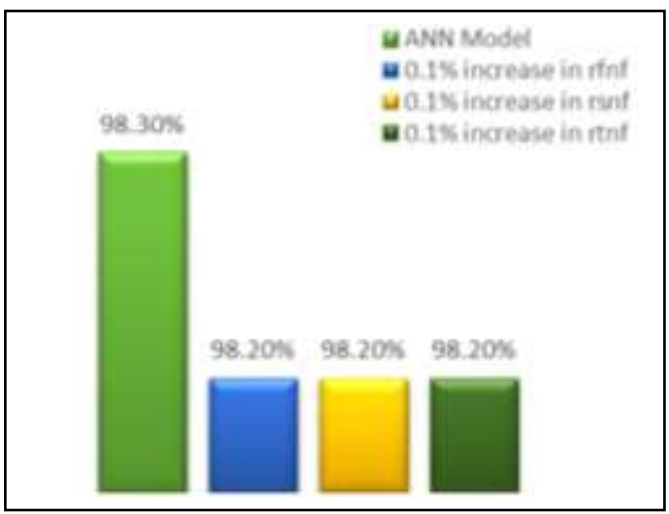

Figure 5. Comparison of R2 Values for Relative crack location by increasing rfnf, rsnf and $\mathrm{rtnf}$ by $0.1 \%$. 


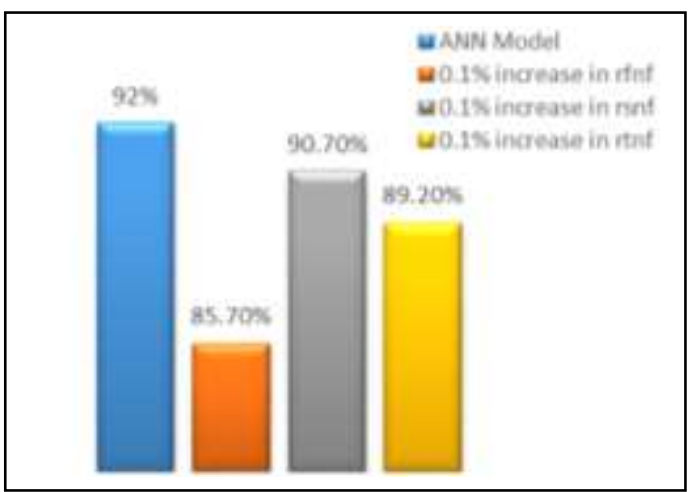

Figure 6. Comparison of R2 Values for Relative crack location by increasing rfnf, rsnf and $\mathrm{rtnf}$ by $0.1 \%$.

It can be seen for the Table $\mathrm{V}$ and Figure 4 and 5 that when a sensitivity analysis was done by changing the input values in order to check whether the proposed model can incorporate uncertainties in it, the results obtained from the ANN model with and without change in the input values has the $\mathrm{R}^{2}$ value close to the original ANN model for the determination of both relative crack depths and relative crack locations. Thus ANN model can be effectively used in damage detection even with some uncertainties in the input data since it produces the best results for finding both rcd and $\mathrm{rcl}$.

\section{vi. Conclusions}

Artificial Neural Networks can be used in developing an effective damage detection algorithm and results obtained from it will be in close proximity with the original values. Even in handling the uncertainty ANN Model gave accurate results. Study should be made to determine the optimum number of hidden layers to be considered and the number of neurons that should be present in each layer. Further Attempts can be made to develop the same algorithms for multiple cracks and also on complex structures.

\section{References}

[1] M. Sahin and R.A. Shenoi," Vibration based Damage Identification in Beam like Composite Laminates by Using Artificial Neural Networks", Journal of Mechanical Engineering Science 217 Part $\mathrm{C}, 2003$.

[2] Rosales, M. B., Filipich, C.P. and Buezas, F.S., Crack detection in beam-like structures, Engineering Structures 31, (2009), 2257-2264.

[3] Bakhary, N., Hao, H. and Deeks, A.J., Damage detection using artificial neural network with consideration of uncertainties, Enginering Stuctures 29, (2007), 2806-2815.

[4] Liu, S.W., Huang Jin H., Sung J.C. and Lee C.C., Detection of cracks using neural networks and computational mechanics, Comput. Methods Appl.Mech. Engrg. 191, (2002), 2831-2845.

[5] Parhi, D.R. and Dash, A.K., Application of neural networks and finite elements for condition monitoring of structures, Journal of Mechanical Engineering Science 225, (2011), 1329-1339.

[6] Parhi, D.R. and Das, H.C., Application of Neural network for fault diagnosis of cracked cantilever beam, World Congress on Nature and Biologically Inspired Computing, NABIC, (2009), 1303-1308.

[7] Saeed, R.A. and Galybin, A.N. and Popov, V., Crack identification in curvilinear beams by using ANN and ANFIS based on natural frequencies and frequency response functions, Neural Comput. and Applic. (2011).
[8] Mahmoud, M.A. and Abu Kiefa M.A., Neural network solution of the inverse vibration problem, NDT AND E International 32, (1999), 9199.

[9] Özkaya, E. and Öz, H.R., Determination of natural frequencies and stability regions of axially moving beams using artificial neural networks method, Journal of Sound and Vibration 252(4), (2002), 782-789.

[10] Nazari, F. and Baghalian, S., A new method for damage detection in symmetric beams using artificial neural network and finite element method, International Journal of Engineering and Applied Sciences (IJEAS) 3, (2011), 30-36.

About Author (s)

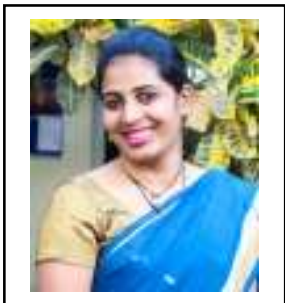

B. Prakruthi Gowd, Assistant Professor Civil Engineering Department and Presently pursuing Ph.D in the field of Structural Health Monitoring. Gold medalist in M.Tech, Structural Engineering. The research area is Damage Detection in Structures using Vibration based Damage Detection Techniques (Wavelet Transforms, Fuzzy Logic and Artificial Neural Network).

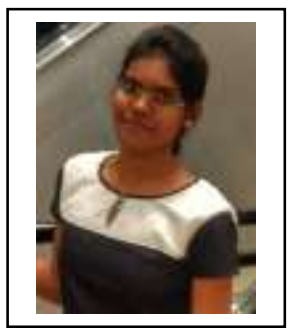

DivyaVani B, Assistant Professor, Civil Engineering Department, M.Tech in Computer Aided Structural Engineering, IIIT Hyderabad, Have published 7 papers including Indian Geotechnical Engineering Conference on Sustainability in Geotechnical Engineering Practices and Related Urban Issue in 2016.

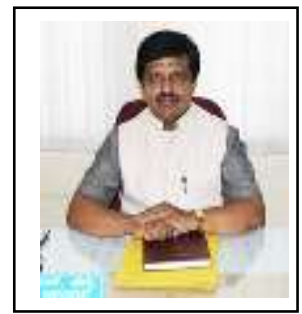

Dr. Manjunatha N. Hegde, DeanAcademic, Professor of Civil Engineering, has obtained $\mathrm{PhD}$ degree in Civil Engineering from Indian Institute of Science (IISc) and has 31 years of teaching and/ research experience. His research area includes FEM in Stochastic Structural Dynamics \& Earthquake Engineering, Fibre Reinforced Concrete, System Identification, Damage Assessment and health Monitoring of Civil Infrastructures, and Life Cycle Energy Cost of Buildings. $\mathrm{He}$ is the member of Professional bodies like IEI, ISTE, ISET, ICI, ACCE (I), and INSTRUCT. He is the Member of Board of Studies and/ Examinations of Autonomous Engineering Colleges under VTU. 